\title{
Syngas Production by Chemical-Looping Gasification of Waste Activated Carbon with Iron-Based Oxygen Carrier
}

\author{
Xiao $\mathrm{Li}^{1,3}$, An $\mathrm{Mei}^{2}$, Man $\mathrm{Wu}^{1}$, Jinshuai $\mathrm{Li}^{1}$, Xiuli Zhang ${ }^{1}$, Qiang Fangyuan ${ }^{1}$, Jilai $\mathrm{Wu}^{1}$, Sijie Yuan ${ }^{1}$, \\ Qingjie Guo ${ }^{1,2 *}$
}

${ }^{1}$ Key Laboratory of Clean Chemical Processing of Shandong Province, College of Chemical Engineering, Qingdao University of Science and Technology, Qingdao, PR China

${ }^{2}$ State Key Laboratory of High-efficiency Coal Utilization and Green Chemical Engineering, College of Chemistry and Chemical Engineering, Ningxia University, Yinchuan, PR China

${ }^{3}$ College of Mathematics and Statics, Qinghai Normal University, Xining, PR China

E-mail: qj guo@yahoo.com

Received: 27 October 2021; Revised: 4 January 2022; Accepted: 15 January 2022

Abstract: Waste Activated Carbon (WAC), as a typical solid waste, can be utilized by Chemical-Looping Gasification (CLG) technology with an iron-based Oxygen Carrier (OC) to produce valuable synthesis gas. A series of experiments on WAC of the CLG process has been performed in a fixed-bed reactor. The operation parameters and cyclic performance of the iron-based OC have been investigated during CLG reactions. Fresh and cyclic reaction OC samples have been analyzed by X-Ray Diffraction (XRD) and Scanning Electron Microscopy (SEM). To obtain high-quality syngas with high carbon conversion, the optimal $\mathrm{OC} / \mathrm{WAC}$ mole ratio, steam flow rate and reaction temperature are $0.1,0.10 \mathrm{~mL} /$ min, and $950^{\circ} \mathrm{C}$, respectively. The iron-based $\mathrm{OC}$ exhibits a stable cyclic performance during multiple tests, following the reaction path of $\mathrm{Fe}_{2} \mathrm{O}_{3}$ to $\mathrm{Fe}_{0.98} \mathrm{O}$ in the individual reduction process. Moreover, the iron-based $\mathrm{OC}$ is oxidized to almost its initial state after 10 redox tests without obvious sintering and agglomeration phenomena. The WAC of CLG provides a new approach to the comprehensive usage of solid waste, especially with low volatile feedstock.

Keywords: chemical looping gasification, cyclic properties, iron-based oxygen carrier, synthesis gas, waste activated carbon

\section{Nomenclature}

$\begin{array}{ll}\text { A } & \text { Ash (wt. \%) } \\ \text { AC } & \text { Activated carbon } \\ \text { CLC } & \text { Chemical looping combustion } \\ \text { CLG } & \text { Chemical looping gasification } \\ \text { CLR } & \text { Chemical looping reforming } \\ \text { FC } & \text { Fixed carbon (wt. \%) } \\ \text { GC } & \text { Gas chromatography } \\ \text { LHV } & \text { Lower heat value }\end{array}$

Copyright (C2022 Qingjie Guo, et al.

DOI: https://doi.org/10.37256/fce.3120221220

This is an open-access article distributed under a CC BY license

(Creative Commons Attribution 4.0 International License)

https://creativecommons.org/licenses/by/4.0/ 


$\begin{array}{ll}\mathrm{M} & \text { The mass of WAC (g) } \\ \mathrm{M} & \text { Moisture (wt. \%) } \\ \mathrm{Me}_{\mathrm{x}} \mathrm{O}_{\mathrm{y}} & \text { Metal oxide } \\ \mathrm{OC} & \text { Oxygen carrier } \\ \mathrm{SEM} & \text { Scanning electron microscopy } \\ \mathrm{SBR} & \text { Polymerized styrene butadiene rubber } \\ \text { TCD } & \text { Thermal conductivity detector } \\ \text { V } & \text { Volatile (wt. \%) } \\ \text { WAC } & \text { Waste activated carbon } \\ \text { WGS } & \text { Water-gas shift } \\ \text { XRD } & \text { X-ray diffraction }\end{array}$

\section{Introduction}

As the best versatile absorbent, AC is extensively used in various industrial processes for decades. ${ }^{1,2}$ Because of the serious pore blockage, some of the spent AC is difficult to regenerate. The WACs are discarded as solid waste. Considering the various disposal methods, gasification is a new way to treat WACs. The CLG technology has attracted attention due to their ability to convert carbonaceous waste to valuable products. ${ }^{3,4}$ Typically, WAC has the advantage of high carbon content. Hence, it is a good candidate as feedstock in the gasification process.

CLG is achieved with OCs, such as $\mathrm{Me}_{\mathrm{x}} \mathrm{O}_{\mathrm{y}}$, which is employed as oxygen source. The OC is continuously transported and circulated between two interconnected chambers. Lattice oxygen released from the OC provides the oxygen required for gasification, which leads to a lower cost without air separation. Meanwhile, it is associated with the inherent separation of $\mathrm{CO}_{2} \cdot{ }^{5}$ Moreover, the lattice oxygen is capable of avoiding combustion reactions by controlling the mole ratio between fuels and OCs. The schematic of CLG process for the synthesis gas production is exhibited in Figure 1.

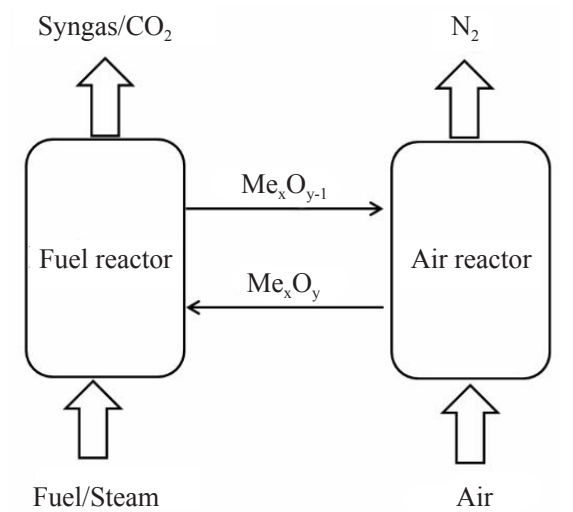

Figure 1. Schematic illustration of the chemical looping gasification with WAC

For the CLG, the design and selection of a proper OC is a crucial point to produce the high quality of syngas. ${ }^{6}$ At present, along with transition metal oxides, i.e., $\mathrm{Ni}, \mathrm{Cu}, \mathrm{Co}, \mathrm{Mn}, \mathrm{Fe}$, that have been investigated as possible oxygen carriers for the CLG process, synthetic oxygen carriers are widely researched, while natural minerals are potentially developed. ${ }^{7,8}$ From which, iron ore as a natural OC was largely used due to its low cost, environmental-friendliness and sulfur resistance. ${ }^{9,10}$ And it indicated that the iron-based oxygen carrier promoted tar cracking and reforming during biomass gasification process, which resulted in increased syngas production. ${ }^{11,12}$ In particular, $\mathrm{Fe}_{2} \mathrm{O}_{3} / \mathrm{Al}_{2} \mathrm{O}_{3}$ demonstrated excellent performance and good stability in the usage of waste resources, such as biomass, sewage sludge, wastewater and municipal solid waste. ${ }^{13}$ The CLG of biomass was studied with $\mathrm{OC}$ of $\mathrm{Fe}_{2} \mathrm{O}_{3} / \mathrm{Al}_{2} \mathrm{O}_{3}$ in a $10 \mathrm{~kW}$ th interconnected 
fluidized-bed reactor. ${ }^{14}$ However, because of the different elemental composition, proximate analysis and physical properties of carbon raw material in the CLG process, the WAC has unique gasification characteristics.

Operating conditions play a key role in significantly influencing the process performance, especially the amount of hydrogen in the product gas. Many researchers have studied the relationship between gasification temperature and process performance, as well as hydrogen production. Elevated temperature improves gas yield and process efficiencies during the CLG process. The CLG temperature of no less than $800{ }^{\circ} \mathrm{C}$ was needed for a complete redox of iron ore to avoid calcium carbonation and enable a sustainable hydrogen. ${ }^{12}$ In a study of biomass CLG using $\mathrm{NiFe}_{2} \mathrm{O}_{4},{ }^{15}$ carbon conversion efficiency, and syngas yield increased approximately $26 \%$ from $700{ }^{\circ} \mathrm{C}$ to $850{ }^{\circ} \mathrm{C}$. The steam flow rate is a key parameter strongly affecting hydrogen production and carbon conversion efficiency, as well as the total gas yield. In the presence of high steam content in the gasifier, there is an increase in both the yield and content of hydrogen. Many researchers have reported that increasing SBR leads to a rise in hydrogen production and carbon conversion efficiency, as well as a small amount of tar produced. ${ }^{8}$ The mole ratio of OC to WAC (OC/WAC) is a key factor in CLG process. OC/WAC strongly influences the composition of the product gas, gas yields, and the performance of the CLG process. An increase in the amount of OC used leads to a further char gasification; therefore, high OC/WAC is beneficial for carbon conversion efficiency. However, it was found that a rise in OC/WAC caused a low content and the yield of $\mathrm{H}_{2}$ and $\mathrm{CO}$ in the product gas. It is due to the higher quantity of oxygen carriers that would promote the oxidation reactions of combustible gases including $\mathrm{H}_{2}$ and $\mathrm{CO}$. Alternatively, a high amount of $\mathrm{OC}$ results in a higher gasification temperature, which enhances the gasification and improves the quality of the product gas to some extent. ${ }^{16,17}$

The resource usage of WAC to produce synthesis gas would be achieved through CLG by opening a broader means for treating carbonaceous solid wastes. This work aims to verify the feasibility of iron-based OCs for the treatment of WAC in CLG, focusing on macroscopic research combined with various analytical methods. A series of experiments were performed to investigate the effect of parameters including the mole ratio of OC to WAC (OC/WAC), reaction temperature and steam flow in the gasification process. Afterward, the stability of the OC during multiple redox reactions was also discussed, and 10-cycle experiments were conducted. Finally, fresh and used OC was collected and analyzed with XRD and SEM to better reveal the crystalline phase transformation and surface morphology changes, respectively. This study is expected to provide basic experimental support for the in-depth research of solid fuel CLG technology.

\section{Materials and experimental details}

\subsection{Materials}

A typical WAC was collected from sugar factory in Shandong Province, China. The samples were dried at $90{ }^{\circ} \mathrm{C}$ for $2 \mathrm{~h}$ and then ground and sieved into an approximate size of 80-200 $\mu \mathrm{m}$. The proximate and ultimate analyses, and lower heating values of the WAC are provided in Table 1.

Table 1. Proximate and ultimate analysis of WAC after pretreatment

\begin{tabular}{|c|c|c|c|c|c|c|c|c|c|c|}
\hline \multirow{2}{*}{ Sample } & \multicolumn{4}{|c|}{ Proximate analysis $w_{\text {ad }}(\%)$} & \multicolumn{5}{|c|}{ Ultimate analysis $w_{\text {ad }}(\%)$} & \multirow[t]{2}{*}{$\begin{array}{c}\text { LHV } \\
(\mathrm{MJ} / \mathrm{kg})\end{array}$} \\
\hline & $\mathrm{A}$ & M & V & $\mathrm{FC}$ & $\mathrm{C}$ & $\mathrm{H}$ & $\mathrm{N}$ & S & $\mathrm{O}^{1}$ & \\
\hline WAC & 11.87 & 1.40 & 37.43 & 55.14 & 71.62 & 2.96 & 3.83 & 1.64 & 3.84 & 14.14 \\
\hline
\end{tabular}

ad: air-dried basis; A: ash (wt. \%); M: moisture (wt. \%); V: volatile (wt. \%); FC: fixed carbon (wt. \%)

${ }^{1}$ : Wt. \% of $\mathrm{O}$ element was calculated by difference

\subsection{Oxygen carrier preparation}

The $\mathrm{Fe}_{2} \mathrm{O}_{3} / \mathrm{Al}_{2} \mathrm{O}_{3} \mathrm{OC}$ was prepared by the impregnation method. A given amount of $\mathrm{Fe}\left(\mathrm{NO}_{3}\right)_{3} \cdot 9 \mathrm{H}_{2} \mathrm{O}$ was dissolved in deionized water for the preparation of the saturated solution. Here, $\mathrm{Al}_{2} \mathrm{O}_{3}$ powder was added into the saturated 
solution as an inert support. Then, the mixture solution was stirred and heated at $80{ }^{\circ} \mathrm{C}$ until the water was evaporated. After that, the residue was dried at $120{ }^{\circ} \mathrm{C}$ for $12 \mathrm{~h}$. Then, it was transferred into a muffle furnace and calcined at $900{ }^{\circ} \mathrm{C}$ for $3 \mathrm{~h}$ under an air atmosphere. Finally, the obtained precursors were crushed and sieved into $\sim 100 \mu \mathrm{m}$.

\subsection{Experimental procedure}

To simplify the CLG reaction process of WACs, a series of experiments were implemented in a fixed-bed reactor to test the feasibility of WAC disposal by CLG. The diagram is illustrated in Figure 2. The proposed apparatus is composed of a quartz tube reactor, a mass flow controller, a steam generator section, a cooling system, an exhaust gas sampling container, and an analysis system. An electronic furnace heated the tube reactor. A thermocouple surrounding the tube controlled the temperature. The steam generator was composed of a constant flow pump for steam generation through preheating by a furnace at $300{ }^{\circ} \mathrm{C}$.

In the reduction stage of each test, a mixture of WAC and $\mathrm{OC}$ with various $\mathrm{OC} / \mathrm{WAC}$ ratios $(0,0.1,0.15,0.2$, and 0.25 ) was initially loaded in a quartz boat and placed on the cool zone of the tube. High-purity argon was used as the purge gas at $200 \mathrm{~mL} / \mathrm{min}$ for $15 \mathrm{~min}$ in advance to remove the air. When the reactor reached the desired reaction temperature $\left(750,800,850,900\right.$, and $\left.950{ }^{\circ} \mathrm{C}\right)$, argon was replaced by a mixture stream of different steam flow rates $(0$, $0.05,0.10,0.15$, and $0.20 \mathrm{~mL} / \mathrm{min}$ ). Next, the argon was used to flush the gasification reactor for $5 \mathrm{~min}$. After that, the quartz boat was rapidly moved into the heating zone, and the gasification time was 60 min, which was sufficient for the reaction. The exit gas was passed through cooling, purifying and drying. Finally, the generated gases were collected via a group of sampling bags at 5-min intervals. During the oxidation period, the reduced OC was oxidized by air at a volumetric flow rate of $200 \mathrm{~mL} / \mathrm{min}$ in a tubular furnace. The oxidation time was set for $60 \mathrm{~min}$. Since the reaction system was a batch system, the OC particles were alternatively exposed to oxidation and reduction stages to simulate the circulating experiments. The compositions of the flue gas were measured by off-line GC with a TCD detector. After the reactor cooled to ambient temperature, the selected OC particles were collected for characterization analysis.

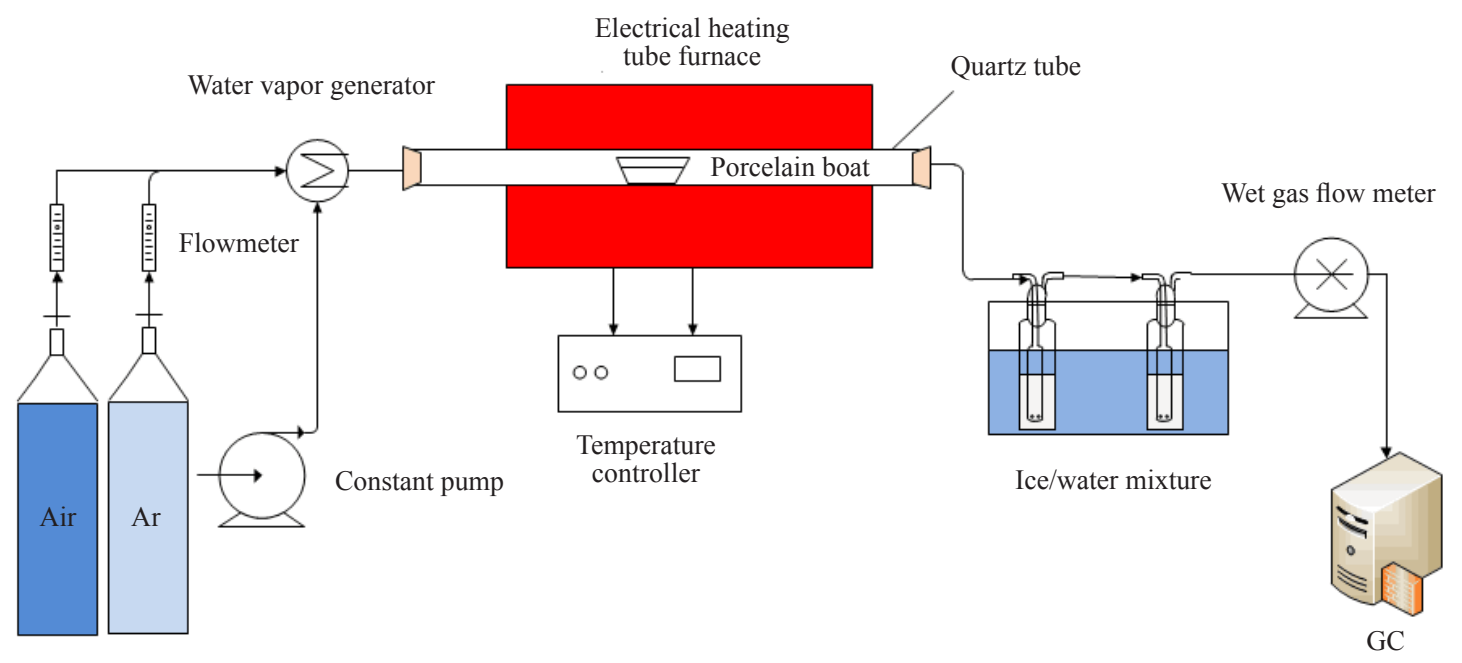

Figure 2. Schematic of a fixed bed reactor

\subsection{Oxygen carrier characterization}

To better understand the reaction mechanism, a series of characterization methods was employed. The crystalline phase of the OC samples was confirmed with XRD using $\mathrm{Cu}-\mathrm{K} \alpha$ radiation with $40 \mathrm{kV}$ and a current of $40 \mathrm{~mA}$. The samples were scanned in the $2 \theta$ range of $5-80^{\circ}$ with a step range of $0.02^{\circ}$. Moreover, SEM using a Hitachi S4800 was used to evaluate the morphology surface features of the $\mathrm{OC}$ samples at different stages. 


\subsection{Data processing}

(1) In each part, the relative gas content $\left(C_{\mathrm{i}}\right)$ of each component in the dry basis outlet gas can be evaluated as follows:

$$
C_{\mathrm{i}}=\frac{\int_{0}^{t} v \cdot y_{\mathrm{i}} d t}{\int_{0}^{t} v \cdot y d t}
$$

Where $y_{\mathrm{i}}$ represents the actual volume fraction of gas species $\mathrm{i}\left(\mathrm{H}_{2}, \mathrm{CO}, \mathrm{CH}_{4}\right.$, and $\left.\mathrm{CO}_{2}\right)$ in dry outlet gas; $v$ denotes the volume flow rate of the dry basis flue gas in the outlet.

(2) The lower heating value ( $\mathrm{LHV}, \mathrm{MJ} / \mathrm{Nm}^{3}$ ) of the generated gas products can be calculated as follows:

$$
\mathrm{LHV}=126 C_{C O}+108 C_{H_{2}}+358 C_{C_{4}}
$$

(3) The gas yield $\left(G_{v}, \mathrm{Nm}^{3} / \mathrm{kg}\right)$ is the volume of dry basis gas product yielded from the unit mass of WAC sample, calculated as follows:

$$
G_{\mathrm{v}}=\frac{\int_{0}^{t} v \cdot\left(y_{\mathrm{CO}}+y_{\mathrm{CO}_{2}}+y_{\mathrm{CH}_{4}}+y_{\mathrm{H}_{2}}\right) d t}{M_{W A C}}
$$

(4) The carbon conversion efficiency of the WAC $\left(\eta_{c}, \%\right)$ is the proportion of the carbon fraction of carboncontaining gas in the outlet gas to the carbon fraction of the WAC fed into reactor, where $C_{C}$ percentage is the carbon content of the WAC:

$$
\eta_{\mathrm{c}}=\frac{12\left(C_{\mathrm{CO}}+C_{\mathrm{CO}_{2}}+C_{\mathrm{CH}_{4}}\right) \cdot G_{\mathrm{v}}}{24.45 \cdot C_{C} \% \cdot M_{\mathrm{WAC}}}
$$

(5) The effective gas content $\left(Y_{\mathrm{g}}, \%\right)$ is defined as the ratio of the volume of effective gases $\left(\mathrm{H}_{2}, \mathrm{CO}, \mathrm{CH}_{4}\right)$ to the total amount of gas produced by WAC:

$$
Y_{\mathrm{g}}=\frac{\int_{0}^{t} v \cdot\left(V_{\mathrm{CO}}+V_{\mathrm{H}_{2}}+V_{\mathrm{CH}_{4}}\right) d t}{\int_{0}^{t} v \cdot\left(V_{C O}+V_{\mathrm{CO}_{2}}+V_{C_{4}}+V_{H_{2}}\right) d t}
$$

(6) The syngas yield $\left(\mathrm{Nm}^{3} / \mathrm{kg}\right)$ is the addition of effective gas yield:

$$
V_{\mathrm{g}}=\frac{\int_{0}^{t} v \cdot\left(y_{C O}+y_{\mathrm{CO}_{2}}+y_{\mathrm{CH}_{4}}\right) d t}{M_{W A C}}
$$

\section{Results and discussion}

\subsection{Effect of (OC/WAC) ratio}

The OC was displayed as an oxygen source and heat carrier. A series of comparison experiments were conducted to obtain the optimal OC/WAC value. Additionally, without an active role, $\mathrm{Al}_{2} \mathrm{O}_{3}$ was used as the bed material for the blank 
experiment for comparison.
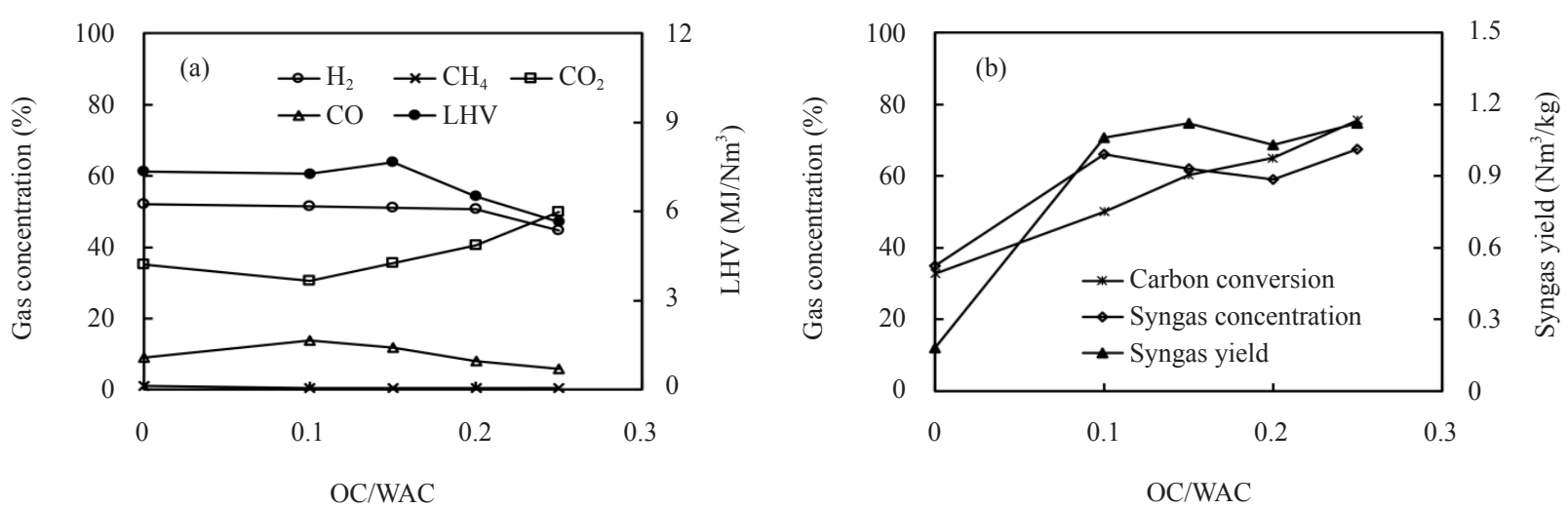

Figure 3. Gasification characteristics of WAC with different mole ratio of OC and WAC at temperatures of $900{ }^{\circ} \mathrm{C}$, steam flow rate at $0.10 \mathrm{ml} / \mathrm{min}$, reaction time of $60 \mathrm{~min}$

The effect of OC and WAC mole ratio on gas distribution and LHV is shown in Figure $3 \mathrm{a} . \mathrm{H}_{2}$ is consumed at first, due to the low activation energy as shown in the reaction (7). Thus, $\mathrm{H}_{2}$ content gradually decreases with the increase of OC/WAC. Reaction (10) was put rightward with the supplement of suitable lattice oxygen. In this condition, the CO concentration firstly increases when $\mathrm{OC} / \mathrm{WAC}$ is lower than 0.1 . However, $\mathrm{CO}$ declines sharply while the $\mathrm{CO}_{2}$ increases monotonously as the OC/WAC increases from 0.10 to 0.25 . A similar result could also be found in a study on iron ore as an oxygen carrier to oxidize biomass char in a fixed bed reactor. ${ }^{18}$ This can be explained that excess lattice oxygen promoted the reactions shown in reactions (7) and (8). The combustible gases were consumed with the generation of $\mathrm{CO}_{2}$ and $\mathrm{H}_{2} \mathrm{O}$. In this case, the gasification process was gradually replaced by combustion process. $\mathrm{CH}_{4}$ content slightly declines with increasing OC/WAC, because of the reaction (9). Meanwhile, LHV firstly increases at the OC/WAC range of 0 to 0.15 , reaching its maximum of $7.67 \mathrm{MJ} / \mathrm{Nm}^{3}$. Then, it abruptly decreases when OC/WAC is exceeded 0.15 with the minimum value of $5.66 \mathrm{MJ} / \mathrm{Nm}^{3}$ at $\mathrm{OC} / \mathrm{WAC}$ of 0.25 . The results meant that extra $\mathrm{OC}$ would provide excess lattice oxygen, causing the consumption of large amount of synthesis gas.

To further understand the effect of OC/WAC in the CLG process, the vital variables of carbon conversion, syngas concentration and syngas yield are shown in Figure 3b. Due to the promotion of the WAC conversion, carbon conversion gradually increases from 32.72 to $75.53 \%$ as the increase of OC/WAC from 0 to 0.25 . Meanwhile, the syngas concentration and syngas yield are up to $67.41 \%$ and $1.12 \mathrm{Nm}^{3} / \mathrm{kg}$, respectively. The result was similar to the study of chemical looping co-gasification of biomass and polyethylene. ${ }^{17}$ It resulted that the syngas generation was evidently enhanced with the addition of OC. The OC was prone to achieve WAC's partial oxidization by producing the target gaseous products. ${ }^{19}$ Besides, the OC enhanced the WGS reaction to generate more $\mathrm{H}_{2}{ }^{20}{ }^{2}$ However, when the OC/WAC was more than 0.1 , syngas concentration and syngas yield drastically decreased. This was mainly attributed to a part of combustible gas that was completely oxidized by the excess lattice oxygen of OC, which was averse to syngas generation. Generally, higher OC/WAC meant more OC added in reactor, which significantly promoted WAC conversion but sacrificed synthesis gas yield. To high-efficiently use WAC, the OC/WAC ratio was determined at 0.15 , where the highest LHV value $7.67 \mathrm{MJ} / \mathrm{Nm}^{3}$ was obtained. The reactions associated with $\mathrm{OC}$ are listed as followed:

$$
\begin{array}{cc}
\mathrm{H}_{2}+1.042 \mathrm{Fe}_{2} \mathrm{O}_{3} \rightarrow 2.127 \mathrm{Fe}_{0.98} \mathrm{O}+\mathrm{H}_{2} \mathrm{O} \quad \Delta \mathrm{H}_{1173 \mathrm{~K}}>0 \Delta \mathrm{G}_{1173 \mathrm{~K}}<0 \\
\mathrm{CO}+1.042 \mathrm{Fe}_{2} \mathrm{O}_{3} \rightarrow 2.127 \mathrm{Fe}_{0.98} \mathrm{O}+\mathrm{CO}_{2} \quad \Delta \mathrm{H}_{1173 \mathrm{~K}}<0 \Delta \mathrm{G}_{1173 \mathrm{~K}}<0 \\
\mathrm{CH}_{4}+4.17 \mathrm{Fe}_{2} \mathrm{O}_{3} \rightarrow 8.511 \mathrm{Fe}_{0.98} \mathrm{O}+\mathrm{CO}_{2}+2 \mathrm{H}_{2} \mathrm{O} \quad \Delta \mathrm{H}_{1173 \mathrm{~K}}>0 \Delta \mathrm{G}_{1173 \mathrm{~K}}<0
\end{array}
$$




$$
\mathrm{C}+1.042 \mathrm{Fe}_{2} \mathrm{O}_{3} \rightarrow 2.127 \mathrm{Fe}_{0.98} \mathrm{O}+\mathrm{CO} \quad \Delta \mathrm{H}_{1173 \mathrm{~K}}>0 \Delta \mathrm{G}_{1173 \mathrm{~K}}<0
$$

\subsection{Effect of steam flow rate}

For further enhancing the WAC conversion and synthesis gas yield, especially the $\mathrm{H}_{2}$ yield, steam was employed as a gasifying agent during the CLG of WACs.

The flue gas concentration and LHV variation under different steam flow rates are shown in Figure 4a. In the absence of steam, the $\mathrm{H}_{2}$ concentration and LHV are the lowest at $17.69 \%$ and $4.18 \mathrm{MJ} / \mathrm{Nm}^{3}$, but $\mathrm{CO}_{2}$ is the highest at $65.07 \%$. With the increasing of steam flow rate, the $\mathrm{H}_{2}$ concentration shows an evident uptrend. Whereas the concentration of $\mathrm{CO}$ decreases overall. The $\mathrm{CH}_{4}$ concentration remains invariable. Based on the evaluations of synthesis gas concentration, the LHV increases substantially from $4.18 \mathrm{MJ} / \mathrm{Nm}^{3}$ to $6.95 \mathrm{MJ} / \mathrm{Nm}^{3}$ as the steam flow rate reaches 0.05 $\mathrm{mL} / \mathrm{min}$. Subsequently, the LHV increases mildly with increasing steam flow rate when the flow rate is higher than 0.10 $\mathrm{mL} / \mathrm{min}$.

The steam flow rate is a key parameter strongly affecting hydrogen production and carbon conversion efficiency, as well as total gas yield. Due to the addition of $\mathrm{H}_{2} \mathrm{O}$, the $\mathrm{H}_{2}$ generation and $\mathrm{CO}$ consumption were facilitated with the reaction (14) shifting toward the right. It was noteworthy that the CO content presented a fluctuation trend, because of the competition effects between reactions (11), (12) and (13). Because the fixed carbon of WACs preferentially reacted with steam to generate $\mathrm{CO}$ rather than undergoing solid-solid reactions between OC and WAC particles. The $\mathrm{CO}_{2}$ concentration decreased overall, and it was much lower than that of without steam. This result suggested that an appropriate steam addition significantly improves the syngas yield, especially $\mathrm{H}_{2}$ generation, which contributed to enhancing the quality of synthesis gas. ${ }^{21}$

Along with the enhancement of hydrogen production, the higher amount of steam used in the gasifier promotes the tar decomposition, which is one of the most serious issues in biomass gasification. It is attributed to tar cracking reactions with the presence of steam. Steam strengthens participation of tar in steam gasification, which leads to a decrease in tar content at higher steam flow rate. Consequently, hydrogen and total gas yields can enhance as products of tar cracking reaction (tar reforming reaction). The addition of steam mainly brings about favorable aspects. Yet, in a large-scale process steam addition is one of the main sources of energy consumption. Hence, one would always try minimizing steam addition to the lowest possible level.
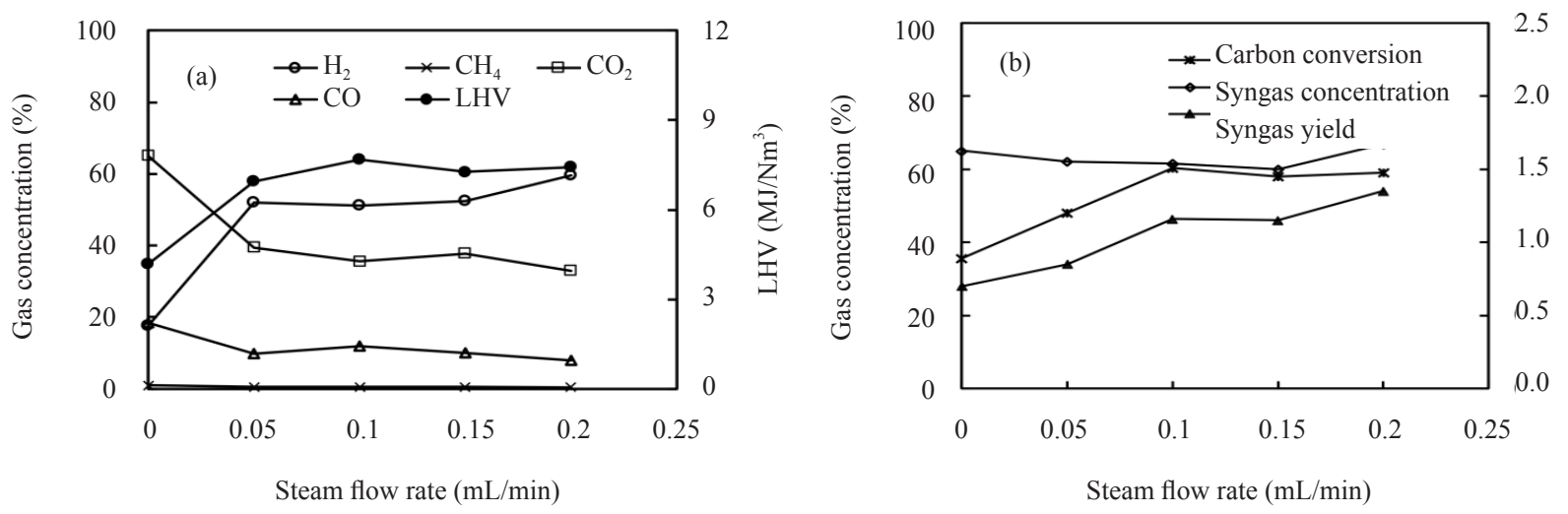

Figure 4. Gasification characteristics of WAC with different steam flow rate at temperatures of $900{ }^{\circ} \mathrm{C}$ $\mathrm{OC} / \mathrm{WAC}$ of 0.15 , reaction time of $60 \mathrm{~min}$

$$
\begin{gathered}
\mathrm{C}+\mathrm{CO}_{2} \rightarrow 2 \mathrm{CO} \quad \Delta \mathrm{H}_{1173 \mathrm{~K}}=+168.84 \mathrm{~kJ} / \mathrm{mol} \\
\mathrm{C}+\mathrm{H}_{2} \mathrm{O} \rightarrow \mathrm{CO}+\mathrm{H}_{2} \quad \Delta \mathrm{H}_{1173 \mathrm{~K}}=+135.71 \mathrm{~kJ} / \mathrm{mol} \\
\mathrm{C}+2 \mathrm{H}_{2} \mathrm{O} \rightarrow \mathrm{CO}_{2}+\mathrm{H}_{2} \quad \Delta \mathrm{H}_{1173 \mathrm{~K}}=+141.3 \mathrm{~kJ} / \mathrm{mol}
\end{gathered}
$$




$$
\mathrm{CO}+\mathrm{H}_{2} \mathrm{O} \rightarrow \mathrm{CO}_{2}+\mathrm{H}_{2} \quad \Delta \mathrm{H}_{1173 \mathrm{~K}}=-41.18 \mathrm{~kJ} / \mathrm{mol}
$$

Additionally, the effect of steam flow rate on carbon conversion, syngas concentration and syngas yield is displayed in Figure 4b. The carbon conversion presents an increasing tendency and then decreases slightly as the increase of steam flow rate with a maximum value of $60.3 \%$ at $0.10 \mathrm{~mL} / \mathrm{min}$. The syngas concentration first decreases and then gradually increases to $66.9 \%$ at $0.20 \mathrm{~mL} / \mathrm{min}$. The syngas yield presents an overall uptrend with the first growing rapidly and then moderates. This have resulted from the reduction reactions being close to chemical equilibrium. On the one hand, the steam evidently promotes carbon conversion and improve the contact between solid reactants as an oxygen source. Accordingly, solid-solid reactions between OC and WAC were improved. ${ }^{18}$ However, the more steam facilitated the WGS reaction to the right to generate more $\mathrm{H}_{2}$. The steam accelerated the syngas yield, especially $\mathrm{H}_{2}$ yield. However, it was notable that the excessive steam $(>0.10 \mathrm{~mL} / \mathrm{min})$ had no plain impact on carbon conversion. Simultaneously, the more steam would shorten the residence time between the gas phase and solid phase. The reactions between the WAC and steam were particularly inhibited. Thus, the WAC conversion and gas yield were restricted within high steam amounts. The flow rate of $0.10 \mathrm{~mL} / \mathrm{min}$ was selected as the proper steam flow rate, where the carbon conversion of $60.3 \%$ and $\mathrm{LHV}$ of $7.15 \mathrm{MJ} / \mathrm{Nm}^{3}$ were achieved.

\subsection{Effect of reaction temperature}

The reaction temperature was a key parameter for fuel conversion and OC performance in the CLG processing. ${ }^{22}$ In this study, a series of experiments corresponding to the effect of gasification temperature on WAC in the CLG was implemented.

Figure 5 depicts the gas distribution and LHV as functions of reactor temperature. The high temperature can drastically improve the WAC conversion and syngas yield. The concentrations of $\mathrm{H}_{2}$ and $\mathrm{CO}$ increase with the increase of temperature, while $\mathrm{CO}_{2}$ presents the opposite trend. For the biomass gasification, the concentrations of $\mathrm{H}_{2}$ reached a peak from $820{ }^{\circ} \mathrm{C}$ to $860{ }^{\circ} \mathrm{C}^{23,24}$ The concentration of $\mathrm{CH}_{4}$ remains constant. According to the increase in combustible gas concentrations, the LHV increases rapidly from $3.72 \mathrm{MJ} / \mathrm{m}^{3}$ at $750{ }^{\circ} \mathrm{C}$ to $7.39 \mathrm{MJ} / \mathrm{m}^{3}$ at $950{ }^{\circ} \mathrm{C}$. Furthermore, the effects of temperature on carbon conversion and syngas concentration are shown in Figure $5 \mathrm{~b}$. As a result, the syngas concentration presents a monotonically increasing trend with the ramping temperature. The carbon conversion increases drastically from 26.59 to $71.54 \%$ as the temperature increased from $750{ }^{\circ} \mathrm{C}$ to $950{ }^{\circ} \mathrm{C}$. Meanwhile, the syngas yield attains the maximum values of $1.47 \mathrm{Nm}^{3} / \mathrm{kg}$ at $950^{\circ} \mathrm{C}$. Accordingly, the high temperature was conducive for WAC thermal conversion and syngas yield.

Temperature is one of the most significant factors in gasification since gasification process is a thermochemical conversion process that uses heat to convert fuel into product gas. Generally, most of the gasification reactions are endothermic reactions, an increase in temperature promotes them. Additionally, higher temperatures increase the heating rate among the particles resulting in effective destruction of the particles and proceeds for complete gasification reactions. ${ }^{25}$ Consequently, more yield of gaseous products is generated, and the amount of unreacted char reduces. The possible explanation supporting this trend can be referred to Le Chatelier's principle. Elevated temperatures favored endothermic reactions (11), (12) and (13), which generated more combustible gases. Additionally, the endothermic reaction (14) was inhibited by a high temperature, which led to the decreasing of $\mathrm{CO}_{2}{ }^{16}$ This indicated that high temperatures were favorable for generating syngas with high calorific values. In addition, the OC presented poor reactivity under low temperatures, leading to limited carbon conversion and syngas products. Accompany the temperature rising, the more lattice oxygen was released. So the WAC conversion was enhanced. A high reaction temperature was necessary to WAC thermal conversion and high-quality synthesis gas yields. At the temperature of $950{ }^{\circ} \mathrm{C}$, the carbon conversion, syngas yield, and LHV attained maximum values were $71.54 \%, 1.47 \mathrm{Nm}^{3} / \mathrm{kg}$, and 7.39 $\mathrm{MJ} / \mathrm{Nm}^{3}$, respectively.

\subsection{Effect of numbers of cycles}

For the OC, one of the main challenges of these processes is to stabilize their performance over prolonged redox cycling. To evaluate the reactivity stabilization of OCs in the CLG process, the multi-cycle tests were performed in a fixed-bed reactor. The reaction temperature, $\mathrm{OC} / \mathrm{WAC}$, steam flow rate, and reaction time were fixed at $950{ }^{\circ} \mathrm{C}, 0.15,0.10$ 
$\mathrm{mL} / \mathrm{min}$ and $60 \mathrm{~min}$, respectively.
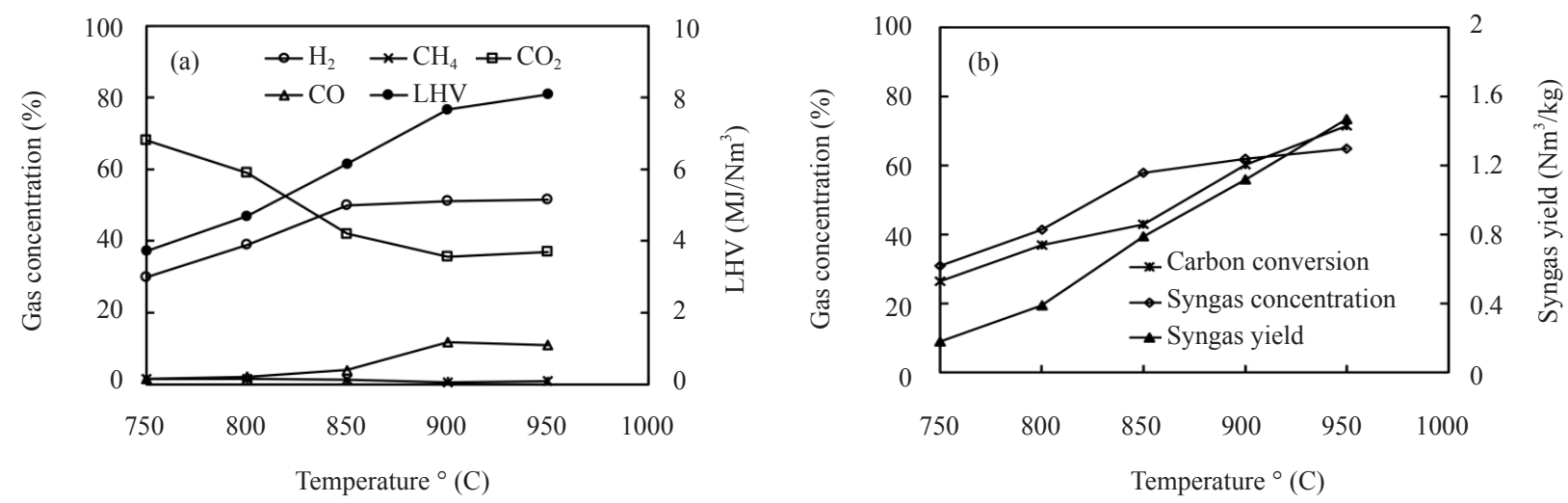

Figure 5. Gasification characteristics of WAC at different temperatures at OC/WAC of 0.15 , steam flow rate of $0.10 \mathrm{ml} / \mathrm{min}$, reaction time of $60 \mathrm{~min}$

As illustrated in Figure 6, the concentration of $\mathrm{CO}_{2}$ shows a slight downward trend with increasing cycle numbers. The $\mathrm{CO}$ concentration presents a slight upward trend. The concentration of $\mathrm{H}_{2}$ also increases at the range from 49.50 to $53.21 \%$ over the cycles. There is no remarkable change in $\mathrm{CH}_{4}$ content. The value of $\mathrm{LHV}$ increases from $7.67 \mathrm{MJ} / \mathrm{Nm}^{3}$ in the first redox cycle to $7.75 \mathrm{MJ} / \mathrm{Nm}^{3}$ in the tenth cycle. The carbon conversion shows a downward trend from 60.31 to $54.11 \%$ during the tests. The syngas concentration gradually increases and reaches the maximum value of $66.88 \%$ in the tenth cycle. Meanwhile, the syngas yield slightly decreases but remains above $1.03 \mathrm{Nm}^{3} / \mathrm{kg}$. Although, the OC reactivity shows a slight deactivation trend after 10 cycles, especially when the oxidation ability of the $\mathrm{OC}$ tends to be moderate, leading to a slight decreasing of $\mathrm{CO}_{2}$ concentration and an elevated calorific value of gases. ${ }^{12} \mathrm{The} \mathrm{Fe}_{2} \mathrm{O}_{3} / \mathrm{Al}_{2} \mathrm{O}_{3}$ still presented a favorable cycle performance in a comparatively long run of cycles for the CLG of WAC.
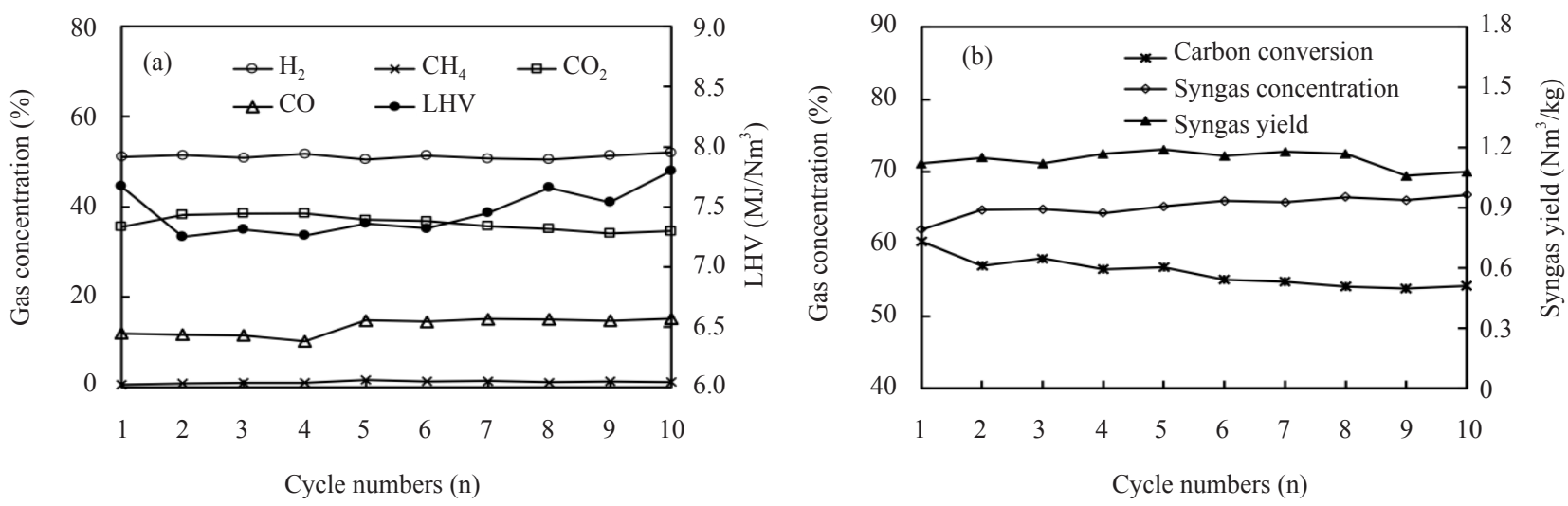

Figure 6. Effect of cycle number on the gasification characteristics of WAC

\subsection{Characterization of $\mathrm{OCS}$}

To further understand the reactivity variation of OCs during the CLG test, the crystalline phase transformation and surface morphology of the OCs were characterized by XRD and SEM. The fresh OC and OC samples after the first reduction and the tenth redox cycle were collected for analysis.

The XRD patterns of the OC samples in different stages are shown in Figure 7. The fresh OC mainly consists 
of $\mathrm{Fe}_{2} \mathrm{O}_{3}$ and $\mathrm{Al}_{2} \mathrm{O}_{3}$. The $\mathrm{Fe}_{2} \mathrm{O}_{3}$ is the active component and $\mathrm{OC}$ to release lattice oxygen. While, the $\mathrm{Al}_{2} \mathrm{O}_{3}$ is the inert carrier. After the first reduction process of the OC in the CLG process, the crystalline phases of $\mathrm{Fe}_{0.98} \mathrm{O}$ and $\mathrm{Al}_{2} \mathrm{O}_{3}$ are detected. This indicated that $\mathrm{Fe}_{0.98} \mathrm{O}$ was the predominant crystal formed from the active component after individual reduction. Meanwhile, little change was observed in the inert $\mathrm{Al}_{2} \mathrm{O}_{3}$ phase. In the tenth cycle sample, the results of main diffraction peak show that $\mathrm{Fe}_{2} \mathrm{O}_{3}$ (PDF: 33-0664) still is the main active constituents and $\mathrm{Al}_{2} \mathrm{O}_{3}$ is the inert constituent.

The active OC component $\mathrm{Fe}_{2} \mathrm{O}_{3}$ was reduced to $\mathrm{Fe}_{0.98} \mathrm{O}$ after $\mathrm{CLG}$ of the WAC. The reduction process of $\mathrm{Fe}_{2} \mathrm{O}_{3} / \mathrm{Al}_{2} \mathrm{O}_{3}$ followed the path of $\mathrm{Fe}_{2} \mathrm{O}_{3}$ to $\mathrm{Fe}_{0.98} \mathrm{O}$. Negative changes to the particles including through sintering and agglomeration occurred during the phase transition from $\mathrm{FeO}$ to $\mathrm{Fe}^{26}$ Although it had no ability to release lattice oxygen and directly reacted with the WAC at high temperature, the unreacted fuel and WAC ash covered the OC surface, which was responsible for the reduction of the $\mathrm{Al}_{2} \mathrm{O}_{3}$ phase. The iron-based $\mathrm{OC}$ was regenerated to its original state over the oxidation stage after multi-redox cycles. Therefore, the XRD results indicated that the iron-based OC had a favorable cycle performance in the CLG process.

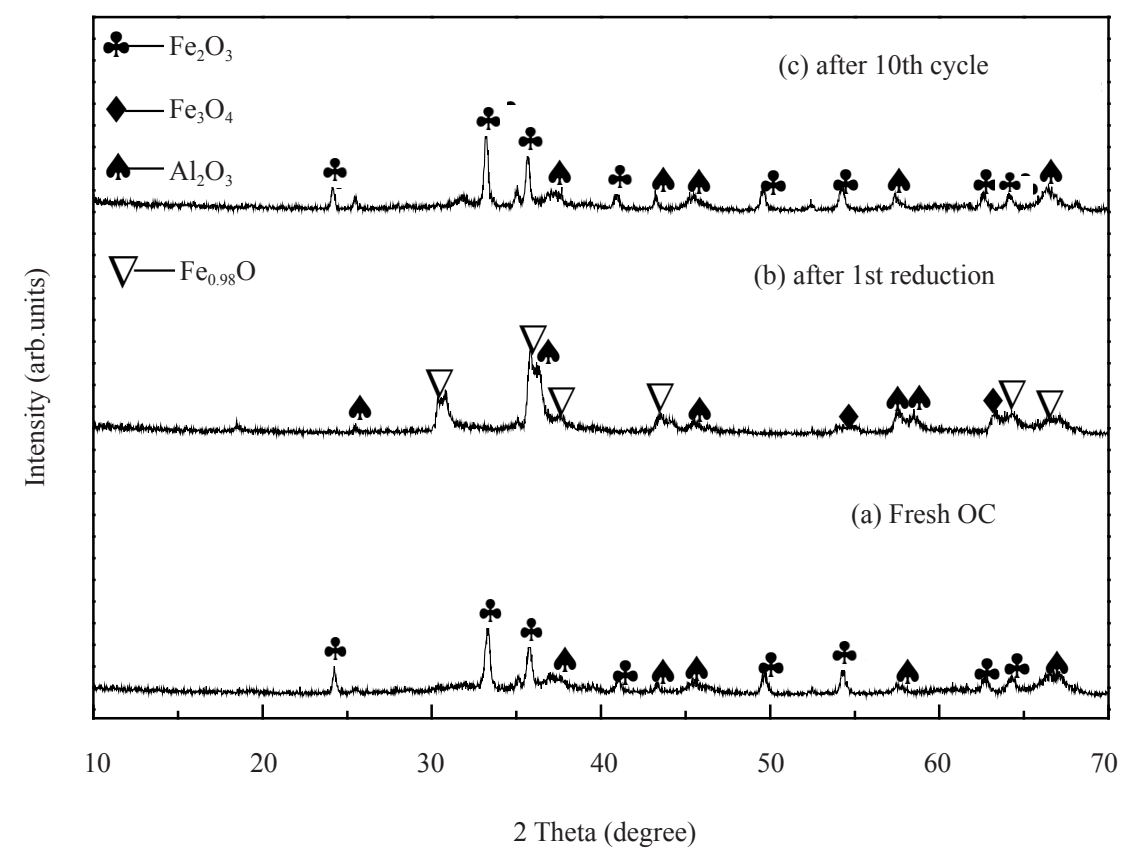

Figure 7. XRD patterns of fresh and used OC samples

SEM was used to evaluate the morphology of OC samples. As illustrated in Figure 8a, the surface structure of the fresh sample is tough and loose with a porous structure. It was beneficial for the diffusion and reactions of reactants. ${ }^{27}$ After the first cycle, the greater porosity structure was observed than that of fresh sample. It was ascribed to gas escaping from the interior of OC particles. ${ }^{20}$ In this case, the structure was conducive for penetrating gaseous reactants into the core of the OC particles. Therefore, the performance of OC was increased in the former cycles. Finally, as shown in Figure 8c, agglomeration is observed in the tenth sample. Some small granules merge into larger granules. It was averse to the reaction between the $\mathrm{OC}$ and other reactants. The surface of the obtained OC was more compact with several agglomerated particles, which was ascribed to the sintering of $\mathrm{Fe}_{2} \mathrm{O}_{3}$ during CLG process, as specified by former papers. ${ }^{28,29}$ Meanwhile, some WAC ash block the pore and cause a negative change to the surface structure as well. ${ }^{30}$ However, it remained porous. These results indicated that iron-based OC was a promising candidate in the WAC CLG process. 


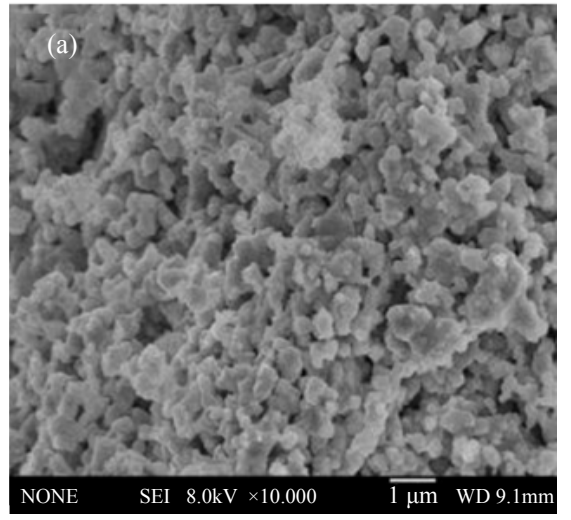

(a) Fresh sample

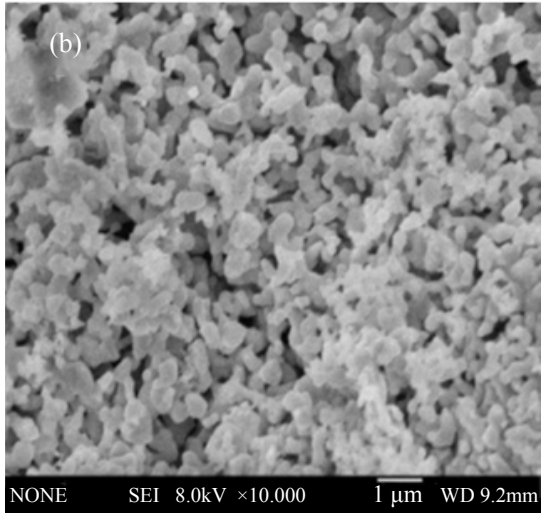

(b) first sample

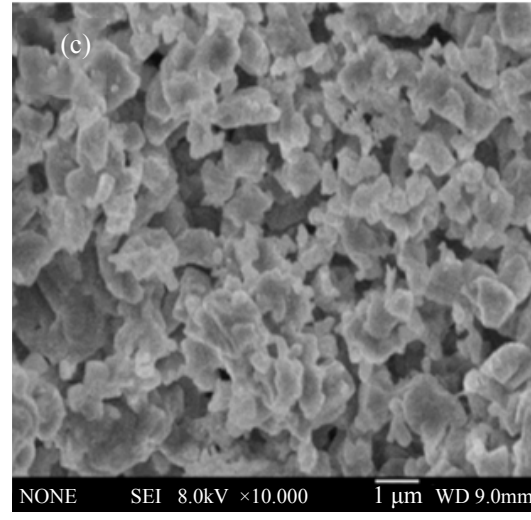

(c) tenth sample

Figure 8. SEM images of Fresh and used OC samples

\section{Conclusions}

This work focused on the production of syngas gas with the WAC as carbon source. An iron-based OC was used in the CLG process. The iron-based OC showed favorable reactivity for syngas generation and WAC conversion. The following conclusions are drawn based on the results:

(1) The introduction of steam promotes WAC conversion and hydrogen generation. The high carbon conversion of $60.31 \%$, yield of syngas product of $1.12 \mathrm{Nm}^{3} / \mathrm{kg}$ and the LHV of $7.67 \mathrm{MJ} / \mathrm{Nm}^{3}$ are reached at the steam flow rate of 0.10 $\mathrm{mL} / \mathrm{min}$, reaction temperature of $950^{\circ} \mathrm{C}$.

(2) The cyclic performances of the OC during 10-time cycle tests are evaluated. Over the long run, no obvious change occurs in the crystalline phase and morphology structure based on the XRD and SEM results. The iron-based OC exhibits good cycling performance.

(3) The $\mathrm{OC}$ follows the reaction path of $\mathrm{Fe}_{2} \mathrm{O}_{3}$ to $\mathrm{Fe}_{0.98} \mathrm{O}$ in the individual reduction process. Then, it is oxidized to the initial state after 10 redox cycle tests. Generally, the comprehensive disposal of WAC by the CLG process with the iron-based oxygen provides a highly efficient and environmentally friendly way.

\section{Acknowledgments}

This work is funded by the Key Projects of National Natural Science Foundation of China (U20A20124); the Key Research and Development Program Project of the Ningxia Hui Autonomous region (2018BCE01002); the National Natural Science Foundation of China (201868025); the National Key Research and Development Program Project (2018YFB0605401); the National First-rate Discipline Construction Project of Ningxia (NXYLXK2017A04); the Shandong Provincial Natural Science Foundation, China (ZR201911170348); the Key Research and Development Program Ningxia (2018BEE03009).

\section{Conflict of interest}

The authors declare no conflict of interest.

\section{References}

[1] Leong, K. Y.; Loo, S. L.; Bashir, M. J. K.; Oh, W. D.; Rao, P. V.; Lim, J. W. Chinese J. Chem. Eng. 2018, 26, 893902. 
[2] Jones, I.; Zhu, M.; Zhang, J.; Zhang, Z.; Preciado-Hernandez, J.; Gao, J.; Zhang, D. J. Clean. Prod. 2021, 312 , 127566-127581.

[3] Arnold, R. A.; Hill, J. M. Energ. Fuel. 2019, 3, 656-672.

[4] Wang, Y.; Niu, P.; Zhao, H. Fuel. Process. Technol. 2019, 192, 75-86.

[5] Zhang, B.; Yang, B.; Guo, W.; Wu, S.; Zhang, J.; Wu, Z. Chinese. J. Chem. Eng. 2021, 36, $233-241$.

[6] Liu, G.; Liao, Y.; Wu, Y.; Ma, X. Int. J. Hydrog. Energ. 2019, 44, 2546-2559.

[7] Xu, D.; Zhang, Y.; Hsieh, T. L.; Guo, M.; Qin, L.; Chung, C. L.; Fan, S.; Tong, A. Appl. Energ. 2018, $222,119-131$.

[8] Nguyen, N. M.; Alobaid, F.; Dieringer, P.; Epple, B. Appl. Sci-Basel. 2021, 11, 7069.

[9] Hu, Q.; Mao, Q.; Ren, X.; Yang, H.; Chen, H. Bioresour. Technol. 2019, 275, 53-60.

[10] Liu, G.; Liao, Y.; Wu, Y.; Ma, X. Energ. Convers. Manage. 2018, 160, 262-272.

[11] Li, Y.; Gong, J.; Huang, F.; Bai, H.; Wang, F.; Wang, C. Energ. Fuel. 2017, 31, 6501-6506.

[12] Hu, Q.; Shen, Y.; Chew, J. W.; Ge, T. S.; Wang, C. H. Chem. Eng. J. 2020, 379, 122346.

[13] Chen, P.; Sun, X.; Gao, M.; Ma, J.; Guo, Q. Chem. Eng. J. 2019, 365, 389-399.

[14] Huseyin, S.; Wei, G. Q.; Li, H. B.; He, F.; Huang, Z. J. Fuel. Chem. Technol. 2014, 42, 922-931.

[15] He, F.; Huang, Z.; Wei, G.; Zhao, K.; Wang, G.; Kong, X.; Feng, Y.; Tan, H.; Hou, S.; Lv, Y.; et al. Energ. Convers. Manag. 2019, 201, 112157.

[16] Yan, J.; Sun, R.; Shen, L.; Bai, H.; Jiang, S.; Xiao, Y.; Song, T. Chem. Eng. J. 2020, 387, 124107.

[17] Liu, Q.; Hu, C.; Peng, B.; Liu, C.; Li, Z.; Wu, K.; Zhang, H.; Xiao, R. Energ. Convers. Manag. $2019,199,111951$.

[18] Huang, Z.; Zhang, Y.; Fu, J.; Yu, L.; Chen, M.; Liu, S.; He, F.; Chen, D.; Wei, G.; Zhao, K.; et al. Int. J. Hydrog. Energ. 2016, 41, 17871-17883.

[19] Wei, G.; Wang, H.; Zhao, W.; Huang, Z.; Li, H. Energ. Convers. Manage. 2019, 185, 774-782.

[20] Deng, Z.; Huang, Z.; He, F.; Zheng, A.; Wei, G.; Meng, J.; Zhao, Z.; Li, H. Int. J. Hydrog. Energ. 2019, 44, 1782317834.

[21] Nguyen, N. M.; Alobaid, F.; May, J.; Peters, J.; Epple, B. Energy. 2020, 202, 117744.

[22] Lin, Y.; Wang, H.; Wang, Y.; Huo, R.; Huang, Z.; Liu, M.; Wei, G.; Zhao, Z.; Li, H. Fang, Y. Energ. Fuel. 2020, 34, 7847-7862.

[23] Zeng, J.; Xiao, R.; Zhang, H.; Wang, Y.; Zeng, D.; Ma, Z. Fuel. Process. Technol. 2017, 168, $116-122$.

[24] Ge, H.; Guo, W.; Shen, L.; Song, T.; Xiao, J. Chem. Eng. J. 2016, 286, 174-183.

[25] Parthasarathy, P.; Narayanan, K. S. Renew. Energ. 2014, 66, 570-579.

[26] Adanez, J.; Abad, A.; Garcia-Labiano, F.; Gayan, P.; Diego, L. Prog. Energ. Combust. 2012, 38, $215-282$.

[27] Das, S.; Deen, N. G.; Kuipers, J. Chem. Eng. J. 2018, 334, 741-759.

[28] Matzen, M.; Pinkerton, J.; Wang, X.; Demirel, Y. Int. J. Greenh. Gas. Con. 2017, 65, 1-14.

[29] Gu, H.; Shen, L.; Zhang, S.; Niu, M.; Sun, R.; Jiang, S. Chem. Eng. J. 2018, 334, 829-836.

[30] Gu, H.; Shen, L.; Zhong, Z.; Zhou, Y.; Liu, W.; Niu, X.; Ge, H.; Jiang, S.; Wang, L. Chem. Eng. J. 2015, 277, 7078. 